\title{
10 \\ Wellbeing and its improvability as a national goal
}

\section{Richard A Burns and Colette Browning}

There is nothing either good or bad, but thinking makes it so

- Hamlet

Wellbeing has long been a discussion point for national policy when considering the impact of social and economic policy. Depending on one's professional outlook, however, we may all arrive at quite different connotations of what wellbeing actually reflects. Consequently, quite different interventions to wellbeing improvement may be considered. Traditionally defined in terms of economic growth and wealth accumulation, more recent wellbeing definitions have incorporated other objective and measurable social indicators including, but not limited to, health-care provision, education access, housing affordability and equality, which have been used to provide an objective measure of quality of life. In contrast, for others, questions of wellbeing relate specifically to the burden of disease and disability in a population, including psychiatric illness (e.g. affective disorders, dementias) and chronic disease (e.g. obesity, diabetes). However, as behavioural scientists, the authors of this chapter relate questions of wellbeing to the experiential and existential dimensions from which we interpret meaning from personal experiences. In this way, wellbeing relates to 
both objective and subjective dimensions of psychological functioning and feeling, often defined in terms of level of cognitive function, affect, motivation and even notions of spirituality.

As definitions and theoretical models of wellbeing determine what is measured, it is important to interrogate how broadly wellbeing is addressed in population surveys. It is important to measure wellbeing beyond economic and social indicators, and to consider the impact of policy on individuals' experiences. But of those measures that have been implemented to date, they have typically focused on clinically relevant dimensions of mental health or individuals' generalised evaluations of their life satisfaction and satisfaction with different life domains (e.g. work, relationships, etc.), ignoring other important psychological indicators of functioning and feeling. One further issue often neglected in population wellbeing is the assumption that all wellbeing dimensions are equally important to all. Whilst one individual prioritises material wealth for their wellbeing, another may prioritise community engagement, and yet another developing a sense of mastery and competence.

Some nations are actively readdressing their approach to measuring population wellbeing. In the United Kingdom (UK) for example, the government is assessing the impact of changes in public policy on changes in personal wellbeing. As part of this process, the government is taking the opportunity to be informed by its citizens; what do they consider important to provide meaning and fulfilment in their own lives? Future national prosperity and wellbeing are outcomes of individuals being enabled to realise their potential (Foresight Report 2008).

In this chapter, we therefore focus specifically on describing the science of wellbeing at the individual level and its importance for populationlevel policy. First we examine current population-level approaches to personal wellbeing that recognise the importance of including social as well as economic indicators of a nation's 'wealth'. We then discuss wellbeing at the individual level, describing a distinction between hedonic wellbeing, with its focus on satisfaction judgements, and eudemonic wellbeing, highlighting the limitations of existing population methods with a focus on satisfaction measures. Next, we use the European Social Survey as a case study to show how multiple measures of wellbeing can be used to describe the effects of public policy across a number of wellbeing dimensions at the population level. We then describe contributions to understanding wellbeing 
in Australia based on two large-scale longitudinal studies. Finally, we reflect on the way forward in terms of incorporating wellbeing outcomes in Australian national policy, and the measurement and data collection issues that need to be addressed.

\section{Current population-level approaches to wellbeing}

Governments and policy advocates have increasingly recognised that traditional economic indicators are insufficient alone to describe a population's wellbeing and so broader indicators that encompass social and cultural factors are increasingly considered. In line with a social determinants of health model, this suggests that personal wellbeing is strongly driven by social, economic and health-service factors (Dahlgren and Whitehead 1991), and that health outcomes are strongly related to the lifestyles people live and the contexts in which they live (Wilkinson and Marmot 2003). For example, the most recent US Federal Interagency Forum on Aging-Related Statistics (FIF-ARS 2012) report, Older Americans 2012: Key Indicators of Well-Being, focused on issues of poverty, sources of income, living arrangements, housing, diet, physical activity, cigarette smoking, air quality, access to health care, etc., as key indicators of older adults' wellbeing. Developed with input from various US federal departments, the forum aimed to:

stimulate discussions by policymakers and the public ... By examining a broad range of indicators, researchers, policymakers, service providers, and the Federal government can better understand the areas of wellbeing that are improving for older Americans and the areas of wellbeing that require more attention and effort (p iv).

There is no doubting the role of employment, financial security, air quality and service provision, etc., in providing necessary social and economic conditions that enable individuals and community to thrive, but we note the report failed to consider how individuals themselves value their lives and their personal sense of wellbeing. Maslow's (1968) theory of the hierarchy of needs describes well a model of need motivation whereby a series of underlying basic physical needs, including safety, food and care needs, require addressing before individuals can strive for higher-level outcomes, such as individual growth and actualising needs. That is, as the most basic 
human needs are satisfied, so the organism can begin to focus on more complex, social, emotional and psychological needs that culminate in higher-order psychological functioning. Reports, such as the FIF-ARS, however, fail to consider this level of human functioning.

Similarly, the recent and long-awaited OECD (2014a) report, How Was Life? Global Wellbeing since 1820, examined social progress over the past two centuries. Again, extending the focus of traditional national accounts from simple examinations of trends in GDP per capita growth, How Was Life? considered development across a number of other social determinants of wellbeing including life expectancy, education, personal security and gender equality. Whilst reflecting an emergence of the appreciation of social indicators of population wellbeing, the report similarly fails to consider dimensions of individual experiences.

There have been a number of attempts to assess individual-level wellbeing in population surveys, however, and a few notable examples will provide some context for our narrative. For instance, the Bhutanese Government, under the auspices of The Centre for Bhutan Studies and Gross National Happiness Research, has undertaken a series of nationally representative wellbeing surveys that eschew economic prosperity for Gross National Happiness (GNH), defined in terms of social and individual wellbeing. The Bhutanese GNH survey measures nine domains of population happiness that encompass measures of ecology, health, community, governance, education, culture and living standards, and, importantly, several indicators of personal wellbeing including life satisfaction, positive and negative affect, and spirituality. Based on the 2010 survey outcomes (Ura et al. 2012), around 90 per cent of the Bhutanese population were identified as happy to some extent with sufficiency across most of the domains for most in the population. However, cross-national comparisons with other objective wellbeing measures reveal troubling patterns: Bhutan ranks poorly for healthy life expectancy, life expectancy, infant mortality, and suicide (WHO 2014). Specifically, healthy life expectancy at birth for males is 58 years (ranked 127th out of 194) and for females 59 years (ranked 138th out of 194) whilst infant mortality for children under one is reported at 30 deaths per 1,000 live births (ranked 69th highest out of 194). And despite Bhutan's focus on 'happiness', age-adjusted suicide rates indicated males reporting 23.1 suicides per 100,000 (ranked 33rd highest out of 172) and females reporting 11.2 suicides per 100,000 (ranked 14th highest out of 172). 
Consequently, serious re-examination of the extent to which the GNH survey accurately reflects the wellbeing of its people is needed. Perhaps their findings reflect an expectancy effect? That is, culturally, happiness is seen as a priority and this drives survey responses?

For our current discussion, at least two implications can be drawn from the survey results. First, whilst the Bhutan GNH survey recognises the importance of measuring personal wellbeing, it is clear, in line with Maslow's proposition, that government policy must first address basic social and economic needs as a priority in order for individuals to subsequently flourish and live healthy lives. Second, in the GNH survey, individual wellbeing is perhaps too narrowly defined. This is an issue we will expand on further in this chapter.

Developed nations have also increasingly focused on reconciling notions of economic and social wellbeing with an understanding of individual wellbeing and happiness. Of particular note was the British Government's announcement in late 2010, to supplement its national accounts with measures of other social and individual wellbeing indicators. Speaking on the need for a new measure of wellbeing, British Prime Minister David Cameron (2010) stated:

let me try and address the suspicion that all this is a bit airy-fairy and a bit impractical. Now, of course, you cannot capture happiness on a spreadsheet any more than you can bottle it. If anyone was trying to reduce the whole spectrum of human happiness into one snapshot statistic I would be the first to roll my eyes and write about it in newspapers. But that's not what this is all about. Just as the GDP figures don't give a full story of our economy's growth, but give us a useful indicator of where we're heading. So, I believe a new measure won't give the full story of our nation's wellbeing, or our happiness or contentment or the rest of it - of course it won't - but it could give us a general picture of whether life is improving, and that does have a really practical purpose. First, it will open up a national debate about what really matters, not just in government but amongst people who influence our lives: in the media; in business; the people who develop the products we use, who build the towns we live in, who shape the culture we enjoy. And second, this information will help government work out, with evidence, the best ways of trying to help to improve people's wellbeing.

In a similar vein, the OECD Better Life Initiative (BLI) includes measures of personal wellbeing that tap: 
aspects of life that matter to people and that shape the quality of their lives. This allows for a better understanding of what drives the wellbeing of people and nations, and what needs to be done to achieve greater progress for all (OECD 2014b).

The Commission on the Measurement of Economic Performance and Social Progress (CMEPSP) report also emphasised the need for governments to shift emphasis from measuring economic production to people's wellbeing (Stiglitz et al. 2009). Increasingly, there is a growing consensus for governments and policymakers to realise the complexities that underpin our understanding of wellbeing at both individual and population levels, and to extend the focus from GDP to other social, community and, increasingly, individual factors as an end goal of national public policy (Forgeard et al. 2011). However, from a behavioural science perspective, there remains a level of debate about current population approaches to the measurement of individual wellbeing. Traditionally informed by individuals' psychological and emotional health, encompassing dimensions of clinical mental health outcomes (e.g. depression, cognitive impairment), there is increasing theoretical and empirical basis for the need to focus on psychological dimensions of wellbeing. Such a focus would relate to questions of personal growth, autonomy and mastery, areas of human functioning that are significant drivers of future human behaviour, but that are yet to have much impact in the national policy sphere. There is a considerable need for population-level approaches to be informed by our scientific knowledge about drivers of psychological and subjective wellbeing to ensure relevance in shaping population behaviour and to assess the impact of social and economic policy on individuals' wellbeing.

\section{Psychological and subjective wellbeing}

Within the behavioural sciences, wellbeing has received considerable focus in recent decades as the interest in 'positive psychology' has featured more prominently in lay and academic literature. It is not, however, a particularly new area of research; it has been a century since Adler's (1929) The Science of Living and over half-a-century since Rogers' (1961) On Becoming a Person. There are therefore many psychological theories, findings and reviews that purport to best describe and measure wellbeing. In essence, wellbeing is a multifaceted construct. In an increasingly dated but still excellent introduction 
to the topic, Ryan and Deci (2001) described research on wellbeing as deriving from two perspectives: 1) the 'hedonic' or Subjective Wellbeing (SWB) approach, which focuses on happiness and defines wellbeing in terms of pleasure attainment and pain avoidance; and 2) the 'eudaimonic' or Psychological Wellbeing (PWB) approach, which focuses on meaning and self-realisation, defining wellbeing in terms of the degree to which a person is fully functioning.

SWB emerged during the $1960 \mathrm{~s} / 70 \mathrm{~s}$ as an attempt to measure quality of life and monitor the impact of social policy on change in individuals' wellbeing (Bradburn 1969). The SWB approach focuses on three components: life satisfaction, the presence of positive mood, and the absence of negative mood (Diener and Lucas 1999). With its philosophical roots in the ancient philosophy of Aristippus, SWB is based on the hedonic principles that pleasure and happiness are of primary concern to the individual, an idea echoed later by Bentham's (1789) 'greatest happiness principle'. SWB reflects people's subjective evaluations of their lives, incorporating an assessment of the range of emotions they experience. These evaluations comprise cognitive and affective interpretations of external events, and reflect an individual's personal assessment of their own life. SWB models have perhaps been the most often utilised within the literature, with life satisfaction a frequently used index of individual wellbeing, particularly in larger population studies (Diener et al. 1999). Bhutan's Gross National Happiness approach is an example of this conceptualisation of wellbeing.

In contrast, PWB has its foundations in eudaimonic assumptions that wellbeing is related to whether individuals live their lives according to their true nature or daimon. Many eudaimonic approaches are critical of hedonism for its focus on momentary pleasure, and disregard of longterm purposefulness and growth. Carol Ryff's (1989a, 1989b) model of Psychological Wellbeing is one PWB approach to the measurement of wellbeing, from gerontological and life-span research, which led to the formulation of six dimensions of PWB: autonomy, positive relations with others, environmental mastery, personal growth, purpose in life, and self-acceptance. Ryff (1989b) argued that these six key areas were consistently identified as indicative of the good life and wellbeing. However, significant overlap between a number of these domains has been reported and suggests that PWB, as operationalised by Ryff, is not so clearly defined (Burns and Machin 2008; Abbott et al. 2006). 
Self-Determination Theory (SDT) (Ryan and Deci 2000) reflects another theoretical approach within the PWB paradigm that clearly delineates three basic psychological needs: autonomy, competence and relatedness. SDT posits that fulfilment of these needs is essential for psychological growth, integrity, life satisfaction, and psychological health, as well as experiences of vitality, vigour or energy and selfcongruence (Huppert 2009).

PWB proponents (e.g. Ryff and Singer 1998) have argued that SWB models are limited in describing long-term positive functioning given SWB's focus on affective states and generalised evaluations of satisfaction, which are highly reactive in the short-term but are relatively stable as this affective reaction returns to individuals' setpoints that appear to be stable over time (Headey and Wearing 1989, 1992). Also, Waterman (1993) has argued that positive functioning may require a degree of effort and discipline that may at times run contrary to the pursuit of short-term happiness. Becker (1992) provides countless examples of people who have lived unjust, pointless lives who have nonetheless been happy in the long run, whilst Brickman et al. (1978) described well the short-term changes in SWB in paraplegics and lottery winners who appear to have returned to their initial SWB levels. Diener (1994) suggests happiness is less an end in itself than a consequence of other, more noble, pursuits. Regardless of these differences, there is growing support for the thesis that PWB and SWB constitute two related yet different approaches to modelling wellbeing (Burns and Machin 2008; Lucas et al. 1996; Compton et al. 1996) and that wellbeing should be considered as both an outcome of lives being lived well, and a driver of future living well.

\section{Mental health and wellbeing}

At this point, it is important to emphasise a distinction between wellbeing and mental health. For some, these terms are synonymous. A leading proponent of positive mental health and wellbeing research, Keyes (2002) described:

mental health as a syndrome of symptoms of positive feelings and positive function in life ... The presence of mental health is described as flourishing, and the absence of mental health, characterized as languishing. 
For Keyes, mental health is operationalised in terms of subjective reports of feelings, not clinically relevant dimensions of mental disorders. Similarly, Huppert and So (2013) emphasise the importance of governments conceptualising wellbeing as positive mental health, which lies 'at the opposite end of a spectrum to the common mental disorders (depression, anxiety)'.

However, the current authors argue that there is a need to clearly discriminate between mental health as the degree to which clinically relevant psychological disturbances are present (e.g. affective disorders), and wellbeing that relates to the presence of non-clinical dimensions of psychological feeling and functioning. Hence wellbeing and mental health reflect two, most probably oblique, factors rather than a single factor. Consequently, those with varying degrees of symptoms of mental illness can be described as possessing mental ill health, with absence of these symptoms reflecting mental health. Those who present with high psychological functioning and positive feelings and low negative feelings can be described as possessing high wellbeing, whilst those low in psychological functioning and low positive feelings and high in negative emotions can be described as possessing low wellbeing.

Surprisingly, support for distinguishing between wellbeing and mental health comes from Keyes (2002) himself, in a paper that examined the concordance of Major Depressive Disorder with flourishing (high emotional 'mental' health) and languishing (low emotional 'mental' health). Keyes (2002) identified 4.7 per cent of the languishers as reporting major depression, while 8.5 per cent (those with moderate mental health) and 0.9 per cent (those flourishing), reported major depression. Hence, major depression was itself not indicative of languishing, nor was possessing moderate mental health or flourishing protective against a major depressive episode. This finding emphasises the additional benefit to extending our notion of mental health to consider issues of psychological wellbeing and the contribution they make to describing how well individuals are living their lives.

Most population-level approaches to the assessment of individual wellbeing have focused on clinically relevant mental disorders, with the subsequent burden of mental ill-health on economic growth, labour force participation and community engagement. For example, 
in Australia, two nationally representative surveys, The National Surveys of Mental Health and Wellbeing (emphasis added) 1997 and 2007, estimated the prevalence of mental disorders in Australia and identified those social factors (e.g. marital status, employment, age and gender) that may indicate which sub-populations were most at risk. But what of 'wellbeing'? In 1997, the General Health Questionnaire (GHQ-12) (a measure used to screen for mental disorders), measured life satisfaction, neuroticism (a personality measure), and self-rated health (SRH). Of these only SRH was included in 2007. Given the theoretical wellbeing models presented earlier, it leaves us asking: Where is this notion of wellbeing?

Sadly, large longitudinal studies that focus on multidimensional dimensions of wellbeing that emphasise personal growth and selffulfilment are lacking, even though the Foresight Report (2008) emphasised several years earlier the need for policy to concern itself as much with the enhancement of wellbeing amongst 'normal' members of a population (as there are simply more of them), as with maintaining appropriate and effective services for those with serious mental ill health. Instead, a dominant medical approach has emphasised the promotion of wellbeing by the identification and treatment of disease and subsequent burden.

With advances in medical technology, and with greater understanding of the way disease develops, much of the health industry has focused on identifying, treating and eradicating diseases, with the implicit assumption that by treating the disease wellbeing is promoted. Most government policy has followed suit. But this position does little to promote the notion of health and wellbeing; that individuals live with disease and illness (e.g. cancer, diabetes, asthma) does not prohibit their capacity to lead fulfilling and meaningful lives, and to experience positive feelings and happiness. Indeed, in the preamble to its constitution, the World Health Organization (WHO 1946) described health as 'a state of complete physical, mental and social wellbeing and not merely the absence of disease or infirmity'. Two points need to be emphasised here. First, health is a 'state' of wellbeing and, second, wellbeing is not 'simply the absence' of a particular disease, rather wellbeing means that one possesses something. Hence, a person can experience wellbeing whilst living with disease, but those living without disease are not necessarily living with wellbeing. 


\section{The limitation of satisfaction judgements as indicators of lives lived well}

Advances in psychology and neuroscience indicate that subjective wellbeing can be measured with a degree of accuracy. The last 20 or so years have seen a concerted effort for economic and policyrelated research to utilise subjective indicators of happiness and life satisfaction as indicators of interpersonal wellbeing (Kahneman et al. 1999). However, despite our earlier description of the way in which personal wellbeing can be operationalised, it is surprising that life satisfaction and satisfaction with different life domains, such as with work, relationships, etc., remain the most frequently utilised measure of individual wellbeing in population studies. In Australia for example, The Household and Income Labour Dynamics in Australia (HILDA) survey (Wooden and Watson 2007) uses multiple dimensions of satisfaction with life domains to measure individual wellbeing and has been used to assess the extent to which Australians are happy with their lives (Cassells et al. 2010). However, there have long been questions regarding the utility of satisfaction as a suitable index of wellbeing. The Cassells et al. (2010) report indicated that 88 per cent of the population was satisfied or very satisfied. This may simply correspond with the proportion of the population without psychological distress at a particular moment, but that so many were satisfied leaves little room to examine whether discriminating degrees of satisfaction is really of substantive benefit. Let us consider two further issues in more detail.

First, consider what is known about life satisfaction, happiness and income. Easterlin's paradox (1974) identified that those with high incomes reported higher levels of happiness, but that increases in US income in the 25 years prior to 1970 were not accompanied by long-term changes in happiness - a decline in the 1960s was reported. Similarly, in Japan, self-reported happiness did not increase from 1958 to 1987 despite a five-fold increase in real income. Whilst others (e.g. Hagerty and Veenhoven 2003) have argued that there is evidence for increasing happiness with increasing income, Easterlin (2005) identified issues with the interpretation of these data and subsequently (Easterlin et al. 2010) reaffirmed the paradox in an analysis of 37 countries. Clark et al. (2012) have suggested that other confounding social factors (e.g. marital status, governance, social equality) drive the purported 
association between level of GDP and wellbeing. They have also highlighted the importance of relative income and wealth compared to level of wealth.

A second example involves a consideration of what is known about life satisfaction and age. Frequently, a curve-linear relationship between age and satisfaction is described, but then in which direction? Are people least satisfied in mid-life when work and family demands are at their highest, or are they most satisfied in mid-life when work and family identities are increasingly cemented and accompanied by job promotion and a growing family network? Clark et al. (2012) have suggested an inverted U-shape is most commonly reported, but Baird et al. (2010) reviewed longitudinal data ( $>20$ years) from the German Socio-Economic Panel and British Household Panel studies and found stable life satisfaction in the German population until age 70, whilst the British population reported increases in mid-life, and substantial declines in late life. In contrast, in Australia, Headey and Warren (2008) did identify life satisfaction as lowest in mid-life, and this corresponds well with what we know about increased suicide rates in mid-life, particularly amongst men. Still, these apparently disparate findings indicate the large differences in life satisfaction across seemingly similar countries.

There are two main reasons for why the existing population wellbeing literature describes such contradictory findings. First, there are issues relating to the validity of global wellbeing indicators. Comparisons of global reports of subjective wellbeing are susceptible to cultural differences in the norms that govern self-descriptions (Diener 2000). Kahneman et al. (2004) have argued that global indicators are typically biased by recency effects and extreme events, and frequently perform poorly in experimental studies as these indicators are susceptible to current mood, context, comparison groups, and survey design.

A second issue relates to differences in survey design and methodology. For example, many population findings relating to age differences in wellbeing are based on single or repeated cross-sectional designs that limit analyses to an examination of between-person differences only. Such designs ignore within-person change and longitudinal designs typically indicate less substantial differences over time. For example, using over 20 years of data from the German SocioEconomic Panel, Headey (2008) identified that for most individuals 
their SWB does not appear to change over the life-span. Only amongst a small proportion, those high in extraversion and/or neuroticism, were long-term changes in levels of life satisfaction reported. Similarly, when adjusting for within-person changes in physical health, Burns et al. (2014a) reported that terminal decline - sudden and rapid decline in the years preceding death - in wellbeing and mental health was fully attenuated.

Relatedly, many longitudinal designs typically report overall a single population-level trajectory despite significant variance around the population slopes. For example, Jivraj et al. (2014) identified significant and substantial wellbeing declines in their analyses of the English Longitudinal Study of Ageing dataset. However, almost three-quarters of the variance was identified around the slope and this can have serious implications for our understanding of the extent of consistency in SWB changes within the population. For example, Burns et al. (2015) identified overall population decline in wellbeing and mental health in late life in a traditional multi-level/latent growth analysis, but when utilising a growth mixture modelling framework, identified wellbeing and mental health decline in only 10 per cent of the population, suggesting 1) stability of wellbeing and mental health over time for most, and 2) that substantial declines in only 10 per cent of the population was enough to drive an overall population decline. Only with further substantial investment in longitudinal cohort studies that adequately assess both within- and between-person effects on various wellbeing indicators over substantial temporal context can appropriate conclusions about the course of wellbeing over the life-course be made.

\section{The European Social Survey: A new approach for modelling personal wellbeing?}

Recognising the limitations of satisfaction judgements, and in the light of the scientific wellbeing literature, a recent collaboration of wellbeing researchers has sought to consolidate the different wellbeing approaches into a coherent measure of national wellbeing that could be used in national and international surveys to: 
systematically assesses key wellbeing variables for representative samples, including positive and negative emotions, engagement, purpose and meaning, optimism and trust, and life satisfaction, as well as satisfaction with specific domains of life (Huppert et al. 2009).

The European Social Survey (ESS) Well-being Module (Huppert et al. 2009) reflects one of the first systematic attempts to reconcile both SWB and PWB approaches, which can be conceptualised in terms of psychological feeling and functioning, reflecting dimensions of SWB and PWB respectively (See Table 1). Huppert et al. (2009) argue that the development of such a module provides an:

opportunity for a richly textured description of how the citizens of Europe experience their lives. It complements more objective data on economic, social and environmental influences on well-being, which can be derived from other items within the ESS and from other data sources. We believe that the Well-being Module will provide invaluable information for behavioural and social scientists, and contribute to the development of policies and practices for enhancing well-being across Europe (p 311).

There is evidence for the utility of using a complex model of wellbeing in population research. For example, using data from the ESS, Clark and Senik (2010) identified that those who emphasised the importance of economic wealth and frequently compared their economic wealth with others were more likely to report lower happiness, optimism, life and job satisfaction, and higher levels of depressive feelings. Also, Hooghe and Vanhoutte (2011) identified that both individual and social factors, such as unemployment, drive wellbeing outcomes, but importantly noted that economic and social factors were more strongly related to wellbeing for those individuals living in communities that were more heterogeneous in nature. That is, wider variability in individuals' economic and social capital resources within a community was associated with lower wellbeing for those with lower capital resources. Plagnol and Huppert (2010) identified significant national differences in volunteering rates between ESS nations, and highlighted the role of government policies that to a large extent may determine levels of volunteering within nations and personal wellbeing. 
Table 1. Conceptual framework of the intra-personal feeling and functioning domains in ESS Well-being Module

\begin{tabular}{|l|l|}
\hline Feeling & Functioning \\
\hline Satisfaction & Autonomy \\
\hline Positive affect & Competence \\
\hline Negative affect & Interest in learning \\
\hline Optimism & Goal orientation \\
\hline Vitality & Sense of purpose \\
\hline Self-esteem & Resilience \\
\hline
\end{tabular}

Source: Adapted from Huppert et al. 2009.

\section{An increasing evidence base in Australia}

Unfortunately, a comparable Australian study that examines the impact of social and economic changes on such a range of wellbeing indicators is not available. However, some of our findings, utilising existing longitudinal Australian studies, may provide evidence for the utility of a more complex approach to assessing personal wellbeing, and identifies a future need for governments to incorporate additional measures that tap multiple dimensions of individual wellbeing in future population surveys. For example, using data from The Dynamic Analyses to Optimize Ageing (DYNOPTA) project (Anstey et al. 2010), a harmonisation of several longitudinal studies of ageing, Burns and colleagues have examined the role of vitality, as one indicator of positive feeling, in promoting positive health outcomes in older adults, in comparison to traditional models examining the effects of mental health or psychological distress. Their findings indicate a poor level of wellbeing is a stronger predictor of the likelihood of falls (Burns et al. 2012), poorer self-rated health (Burns et al. 2014b), and mortality (Burns et al. 2015a).

Using data from the PATH study (Anstey et al. 2011), Burns and colleagues (Burns, Anstey and Windsor 2009) have explored both psychological functioning and feeling across the life-span, particularly in relation to mental health outcomes. They explored the temporal associations between measures of SWB or psychological feeling, reflected by positive and negative affect, and PWB or psychological functioning, reflected by mastery/competence and resilience, with 
measures of depression and anxiety. They identified strong support for a model whereby SWB mediated the effects of PWB on depression and anxiety. That is, perceptions of mastery and resilience drove positive and negative feelings, which in turn predicted depression and anxiety outcomes. More recent evidence indicates psychological functioning and feeling to be more sensitive to external life events and work strain (Burns et al. 2016; Burns 2014).

There is clearly a need for future population studies in Australia to consider implementing measures that tap a greater array of human functioning. This will allow a more detailed examination of the effects of policy change on individuals' lives, reflected by changes in their wellbeing. Relatedly, in the UK, following Cameron's (2010) announcement, the Office of National Statistics' survey of national wellbeing now utilises an array of wellbeing and mental-health indicators that identify levels of depression and anxiety, and also reports on happiness, anxiousness, satisfaction and worthwhileness Matheson (2011).

\section{The way forward: Implications for policy directions}

A number of conceptual issues need to be addressed in order to provide robust wellbeing measurement frameworks that can be used to monitor the impact of policy on national wellbeing. First, levels of wellbeing may be of secondary importance to the stability of wellbeing levels over time. Research by Kernis et al. (1998) has demonstrated that wellbeing researchers should perhaps be less focused on levels of wellbeing than the stability of wellbeing over time. Their study investigated the role of self-esteem in the development of depressive symptoms and their findings indicated that level of self-esteem was not a risk for increased depressive symptomology, whilst greater selfesteem variability was a significant risk factor. These findings echo earlier reports (Roberts and Monroe 1992), where even individuals with low self-esteem were likely to report less depressive symptoms than those individuals with high but unstable self-esteem. The importance of this lies in the proposition that the degree of emotional reactivity could be more important as an indicator of health outcomes than level of wellbeing, but this requires longitudinal designs with multiple assessments to capture intra-individual wellbeing variation. 
A second related issue is the extent to which different wellbeing dimensions are weighted equally for all individuals. Different wellbeing dimensions may not be of the same importance for all. One person may emphasise the need for positive relationships while, for another, spiritual growth may be more important. And it is likely that the rank importance of these wellbeing dimensions changes over the life-course as a consequence of normative age experiences (e.g. widowhood, unemployment). For example, Ryff (1991) identified significant differences in the importance of different wellbeing dimensions across the life-course. Whilst middle- and older-aged adults prioritised the importance of social connections, middle-aged adults placed greater emphasis than older-aged adults on the need for a future time perspective, assertiveness and self-acceptance.

Given the malleability of personal wellbeing, the role of public policy in promoting policy demands serious consideration. However, as wellbeing is defined here in terms of psychological functioning and feeling, one may well ask whether we would want government intervening at the individual level where wellbeing reflects the individual's lived experience.

Frey and Stutzer (2012) propose that wellbeing research does not offer an approach to public policy:

Citizens as ultimate decision makers are disregarded, and governments are seen as benevolent maximizers of social welfare ... This view neglects that people differ in what judgments they consider to reflect their normative preferences. Moreover, the processes of adaptation and aspiration change require a decision on how to treat them in policy decisions. This decision is not part of the social welfare maximization approach ... the social welfare approach neglects the negative incentives for manipulating empirical welfare measures ( $p$ 671).

Perhaps more appropriate is a social determinants approach and an examination of the role public policy can make in shaping lives by providing the economic and social foundations upon which citizens live their lives and promote their wellbeing. Such policies could relate to current policy areas such as the provision of safe and healthy workplaces free from harassment, bullying and discrimination; aged-care provision that is driven by the needs of individual consumers; and affordable and accessible health care that prioritises prevention of chronic disease and mental ill health. Frey and Stutzer's (2012) conclusion placed the focus 'thus on rules and institutions rather than on specific policy interventions' (p 671). 
Relatedly, the National Economic Foundation's Five Ways to Wellbeing report (Aked et al. 2008) is one example of an evidenced-based set of policy directions that has been implemented at varying levels of UK governance, from Westminster to local UK councils, to promote population wellbeing. Commissioned by Foresight to examine evidence and develop public health messages concerned with promoting and maintaining positive mental health, the Five Ways to Wellbeing program focuses on engaging individuals to 1) connect with others, 2) be active life participants, 3) take time to notice people and the world around them, 4) continue to strive for learning and knowledge, and 5) express gratitude through giving to others. Rather than developing wellbeing policies per se, their recommendations emphasised the need for policymakers to consider 1) the capacity of their policies to enable citizens to engage with one or all of these wellbeing pathways, and 2) the need to examine the impact of emerging policies on a range of individual wellbeing dimensions. For example, Frey and Stutzer (2000) identified that in Switzerland, those cantons that afforded citizens with greater rights and opportunities to propose and vote on laws and constitutional amendments reported higher personal wellbeing outcomes.

Marmot (2014) summarises a number of areas whereby national policy can intervene to promote public mental health. These include a focus on 1) psychosocial development and medical health in early childhood, 2) access to education and lifelong learning, 3) fair and equitable working conditions, 4) an income to satisfy conditions for health living, including a social security net, 5) safe communities, and 6) sustainable housing; and a recognition of the importance of social determinants in the prevention of poor health outcomes. In a similar vein, we would argue that such measures will also facilitate improvements in flourishing and feeling. The role of government and advocates is then in promoting policies that build the social and economic foundations upon which citizens can flourish. And, as we have importantly emphasised throughout this chapter, the extent to which we adequately capture a range of functioning and feeling outcomes.

Future population-level approaches to measuring wellbeing need to examine the question of what it is for an individual to feel that they live well, with a sense of vigour, vitality and engagement, in the context of work, families, and communities, both within and between nations. This involves extending our focus on dimensions of mental health and generalised evaluations of life satisfaction to encompass 
dimensions of psychological function and feeling. However, there are considerable limitations in the existing research base in understanding the way factors enhance or adversely impact on people's wellbeing over the life-course.

There is a need for longitudinal cohort studies to examine how different socioeconomic experiences impact across the life-course and to understand how life experiences shape older adults' capacity to age well, in health, social and economic terms. In addition, future longitudinal cohort studies require multidisciplinary approaches in order to ensure they maintain relevance with the research base. Such capacities in Australia are considerably limited by current funding models and by study designs that are not multidisciplinary. As we have described, much of the capacity to understand individual-level wellbeing in existing population studies is limited. Such limitations can be overcome with appropriate reference to the scientific literature, as it continues to evolve. The Dynamic Analyses to Optimise Ageing project (Anstey et al. 2010) provides one example of how a multidisciplinary approach, with leading experts from the psychological, social, medical and statistical sciences, could examine ageing experiences from a bio-psychosocial perspective using existing longitudinal data. Currently, within CEPAR, there is an emphasis on combining these perspectives with an attempt to understand the economic foundations which underpin successful and healthy ageing. However, new cohort studies that may inform the impact of social and economic policy changes on future wellbeing demands are sorely needed.

\section{References}

Abbott Rosemary, Ploubidis George, Huppert Felicia, Kuh Diana, Wadsworth Michael and Croudace Tim (2006). Psychometric evaluation and predictive validity of Ryff's psychological wellbeing items in a UK birth cohort sample of women. Health and Quality of Life Outcomes, 4: 76.

Adler Alfred (1929). The Science of Living. New York: Anchor Books.

Aked Jody, Marks Nic, Cordon Corrina and Thompson Sam (2008). Five ways to wellbeing: The evidence. A report presented to the Foresight Project on communicating the evidence base for improving people's well-being. London: The New Economics Foundation. 
Anstey Kaarin, Byles Julie, Luszcz Mary, Mitchell Paul, Steel David, Booth Heather, Browning Colette, Butterworth Peter, Cumming Robert, Healy Judith, Windsor Tim, Ross Lesley, Bartsch Lauren, Burns Richard, Kiely Kim, Birrell Carole, Broe Tony, Shaw Jonathan, Kendig Hal (2010). Cohort profile: The dynamic analyses to optimize ageing (DYNOPTA) project. International journal of Epidemiology, 39: $1,44-51$.

Anstey Kaarin, Christensen Helen, Butterworth Peter, Easteal Simon, Mackinnon Andrew, Jacomb Trish, Maxwell Karen, Rodgers Bryan, Windsor Tim, Cherbuin Nicolas and Jorm Anthony (2011). Cohort Profile: The PATH Through Life Project. International Journal of Epidemiology, 41(4), 951-960. doi: 10.1093/ije/dyr025.

Baird Brendan, Lucas Richard and Donnellan Brent (2010). Life Satisfaction Across the Lifespan: Findings from Two Nationally Representative Panel Studies. Social Indicators Research 99(2): 183-203.

Becker Gary (1992). Habits, Addictions, and Traditions. Kyklos, 45: $327-346$.

Bentham Jeremy (1789). An introduction to the principles of morals and legislation. Oxford: Clarendon Press.

Bradburn Norman (1969). The structure of psychological well-being. Chicago: Aldine.

Brickman Philip, Coates Dan, Janoff-Bulman Ronnie (1978). Lottery Winners and Accident Victims: Is Happiness Relative? Journal of Personality and Social Psychology, 36(8): 917-927.

Burns Richard (2014). Mental Health and Wellbeing Across the Lifespan: Implications for healthy ageing outcomes. Presentation to the APS Ageing-Special Interest Group. 16 May, Adelaide, Australia.

Burns Richard and Anstey Kaarin (2011). Positive and Negative Mental Health Dimensions report differential non-linear effects on mortality. 64th Annual Scientific Meeting of the Gerontological Society of America 18-23 November, Boston, USA. 
Burns Richard, Anstey Kaarin and Windsor Tim (2009). Subjective well-being mediates the effects of resilience and mastery on depression and anxiety in a large community sample of young and middle-aged adults. Australian and New Zealand Journal of Psychiatry, 45(3): 240-248.

Burns Richard, Butterworth Peter and Anstey Kaarin (2016). An examination of the long-term impact of job strain on mental health and wellbeing over a 12-year period. Social Psychiatry and Psychiatric Epidemiology, 51(5): 725-733. doi: 10.1007/s00127-0161192-9.

Burns Richard, Butterworth Peter, Browning Colette, Byles Julie, Luszcz Mary, Mitchell Paul, Shaw Jonathan and Anstey Kaarin (2015a) Examination of the association between mental health, morbidity and mortality in late life: Findings from longitudinal community surveys. International Psychogeriatrics, 27(5): 739-746.

Burns Richard, Byles Julie, Magliano Dianna, Mitchell Paul and Anstey Kaarin (2015b) The utility of estimating populationlevel trajectories of terminal wellbeing decline within a growth mixture modelling framework. Social Psychiatry and Psychiatric Epidemiology, 50(3): 479-487.

Burns Richard, Byles Julie, Mitchell Paul and Anstey Kaarin (2012). Positive components of mental health provide significant protection against likelihood of falling in older females over a 13-year period. International Psychogeriatrics, 24(9): 1419-1428.

Burns Richard and Machin Tony (2008). Investigating the Structural Validity of Ryff's Psychological Well-Being Scales Across Two Samples. Social Indicators Research, 93(2): 359-375.

Burns Richard, Mitchell Paul, Shaw Jonathan and Anstey Kaarin (2014a). Trajectories of terminal decline in the well-being of older women: The DYNOPTA project. Psychology and Aging, 29(1): 44-56.

Burns Richard, Sargent-Cox Kerry, Mitchell Paul and Anstey Kaarin (2014b) An examination of the effects of intra and inter-individual changes in wellbeing and mental health on self-rated health in a population study of middle and older-aged adults, Social Psychiatry and Psychiatric Epidemiology, 49(11): 1849-1858. 
Cameron The Rt Hon David (2010). PM speech on wellbeing, 25 November 2010. www.gov.uk/government/speeches/pm-speechon-wellbeing. Accessed 18 October 2014

Cassells Rebecca, Gong Cathy and Keegan Marcia (2010). The pursuit of happiness: Life satisfaction in Australia, AMP-NATSEM Income and Wealth Report, Issue 26, Sydney.

Clark Andrew, Layard Richard and Senik Claudia (2012). The causes of happiness and misery. UN World Happiness Report, pp. 59-89.

Clark Andrew and Senik Claudia (2010). Who compares to whom? The anatomy of income comparisons in Europe. The Economic Journal, 120: 573-594.

Compton William, Smith Maggie, Cornish Kim and Qualls Donald (1996). Factor structure of mental health measures. Journal of Personality and Social Psychology, 71: 406-413.

Dahlgren Goren and Whitehead Margaret (1991). Policies and strategies to promote social equity in health. Stockholm: Institute for Future Studies.

Diener Ed (1994). Assessing subjective well-being: Progress and opportunities. Social Indicators Research, 31: 103-157.

Diener Ed (2000). Subjective Wellbeing: The Science of Happiness and a Proposal for a National Index. American Psychologist, 55(1): $34-43$.

Diener Ed and Lucas Richard (1999). Personality and subjective wellbeing. In D Kahneman, E Diener, and N Schwarz (Eds) Well-being: The foundations of hedonic psychology. New York: Russell Sage Foundation, pp. 213-229.

Diener Ed, Suh Eunkook, Lucas Richard and Smith Heidi (1999). Subjective Well-Being: Three Decades of Progress. Psychological Bulletin, 125(2): 276-302.

Easterlin Richard (1974). Does Economic Growth Improve the Human Lot? Some Empirical Evidence. In Paul A David and Melvin W Reder (Eds) Nations and Households in Economic Growth: Essays in Honor of Moses Abramovitz. New York: Academic Press. 
Easterlin Richard (2005). Feeding the Illusion of Growth and Happiness: A Reply to Hagerty and Veenhoven. Social Indicators Research, 74(3): 429-443.

Easterlin Richard, McVey Laura, Switek Malgerzata, Sawangfa Onnicha, Zweig Jacqueline (2010). The happiness-income paradox revisited. Proceedings of the National Academy of Sciences, 107(52): 22463.

Federal Interagency Forum on Aging-Related Statistics (FIF-ARS) (2012). Older Americans 2012: Key Indicators of Well-Being. Washington, DC: US Government Printing Office.

Foresight Report (2008). Mental Capital and Wellbeing: Making the most of ourselves in the 21st century: Final project report. London: Government Office for Science.

Forgeard Marie, Jayawickreme Eranda, Kern Margaret and Seligman Martin (2011). Doing the right thing: Measuring wellbeing for public policy. International Journal of Wellbeing 1(1): 79-106.

Frey Bruno and Stutzer Alois (2000). Happiness, economy and institutions. Economic Journal 110(466): 918-938.

Frey Bruno and Stutzer Alois (2012). The use of happiness research for public policy. Social Choice and Welfare, 38: 659-674.

Hagerty Michael and Veenhoven Ruuf (2003). Wealth and Happiness Revisited-Growing National Income Does Go with Greater Happiness. Social Indicators Research 64: 1-27.

Headey Bruce (2008). The Set-Point Theory of Well-Being: Negative Results and Consequent Revisions. Social Indicators Research, 85: 389-403.

Headey Bruce and Wearing Alexander (1989). Personality, life events and subjective well-being: Toward a dynamic equilibrium model. Journal of Personality and Social Psychology, 57: 731-739.

Headey Bruce and Wearing Alexander (1992). Understanding happiness: A theory of subjective well-being. Melbourne, Australia: Longman Cheshire. 
Headey Bruce and Warren Diana (2008). Families, Incomes and Jobs, Volume 3: A Statistical Report on Waves 1 to 5 of the HILDA Survey. Melbourne Institute of Applied Economic and Social Research, University of Melbourne.

Hooghe Marc and Vanhoutte Bran (2011). Subjective well-being and social capital in Belgian communities. The impact of community characteristics on subjective well-being indicators in Belgium. Social Indicators Research, 100(1): 17-36.

Huppert Felicia (2009). Psychological Well-being: Evidence Regarding its Causes and Consequences. Applied Psychology: Health and WellBeing, 1(2): 137-164.

Huppert Felicia and So Timothy (2013). Flourishing Across Europe: Application of a New Conceptual Framework for Defining WellBeing, Social Indicators Research, 110(3): 837-861.

Huppert Felicia, Marks Nic, Clark Andrew, Siegrist Johannes, Stutzer Alois, Vittersø Joar and Wahrendorf Morten (2009). Measuring Well-being across Europe: Description of the ESS Well-being Module and Preliminary Findings. Social Indicators Research, 91(3): 301-315.

Jivraj Stephen, Nazroo James, Vanhoutte Bran and Chandola Tarani (2014). Aging and Subjective Well-Being in Later Life. Journals of Gerontology, Series B: Psychological Sciences and Social Sciences, 69(6). doi: 10.1093/geronb/gbu00.

Kahneman Daniel, Diener Ed and Schwarz Norbert (Eds) (1999). Wellbeing: Foundations of hedonic psychology. New York: Russell Sage Foundation Press.

Kahneman Daniel, Krueger Alan, Schkade David, Schwarz Norbert and Stone Arthur (2004). Toward National Wellbeing Accounts. American Economic Review 94: 429.

Kernis Michael, Whisenhunt Connie, Waschull Stephanie, Greenier Keegan, Berry Andrea, Herlocker Caryn and Anderson Craig (1998). Multiple Facets of Self-Esteem and their Relations to Depressive Symptoms. Personality and Social Psychology Bulletin, 24(6): 657-668.

Keyes Corey (2002). The mental health continuum: From Languishing to Flourishing in Life. Journal of Health and Social Research, 43: 207-222. 
Lucas Richard, Diener Ed and Suh Eunkook (1996). Discriminant validity of well-being measures. Journal of Personality and Social Psychology, 71: 616-628.

Matheson Jil (2011). Measuring what matters: National statistician's reflections on the National Debate on measuring National Well-being. Office of National Statistics. Newport, South Wales. www.ons.gov.uk.

Marmot Michael (2014). Commentary: Mental health and public health. International Journal of Epidemiology, 43(2): 293-296. doi: 10.1093/ije/dyu054.

Maslow Abraham (1968). Toward a psychology of being (2nd edition). New York: Van Nostrand.

Organisation for Economic Co-operation and Development (OECD) (2014a). How Was Life? Global Wellbeing since 1820. www. oecd.org/statistics/how-was-life-9789264214262-en.htm. Accessed 12 October 2014.

Organisation for Economic Co-operation and Development (OECD) (2014b). Better Life Index Executive Summary, 2014. www. oecdbetterlifeindex.org. Accessed 12 October 2014.

Plagnol Anke and Huppert Felicia (2010). Happy to help? Exploring the factors associated with variations in rates of volunteering across Europe. Social Indicators Research, 97(2): 157-176.

Roberts John and Monroe Scott (1992). Vulnerable self-esteem and depressive symptoms: Prospective findings comparing three alternative conceptualizations. Journal of Personality and Social Psychology, 62(5): 804-12.

Rogers Carl (1961). On Becoming a Person. Oxford: Houghton Mifflin.

Ryan Richard and Deci Edward (2000). Self-determination theory and the facilitation of intrinsic motivation, social development, and well-being. American Psychologist, 55: 68-78.

Ryan Richard and Deci Edward (2001). On happiness and human potentials: A review of research on hedonic and eudaimonic wellbeing. Annual Review of Psychology, 52: 141-166. 
Ryff Carol (1989a). Beyond Ponce de Leon and life satisfaction: New directions in quest of successful aging. International Journal of Behavioral Development, 12: 35-55.

Ryff Carol (1989b). Happiness is everything, or is it? Explorations on the meaning of psychological well-being. Journal of Personality and Social Psychology, 57: 1069-1081.

Ryff Carol (1991). Possible selves in adulthood and old age: A tale of shifting horizons. Psychology and Aging, 6: 286-295.

Ryff Carol and Singer Burton (1998). The contours of positive human health. Psychological Inquiry, 9: 1-28.

Stiglitz Joseph, Sen Amartya and Fitoussi Jean-Paul (2009). Report by the Commission on the Measurement of Economic Performance and Social Progress. www.stiglitz-sen-fitoussi.fr/documents/rapport_ anglais.pdf. Accessed 10 November 2010.

Ura Karma, Alkire Sabina, Zangmo Tshoki and Wangdi Karma (2012). A Short Guide to Gross National Happiness Index. Thimphu, Bhutan: The Centre for Bhutan Studies. www.bhutanstudies.org.bt. Accessed 1 November 2014.

Waterman Alan (1993). Two conceptions of happiness: contrasts of personal expressiveness (eudaimonia) and hedonic enjoyment. Journal of Personality and Social Psychology, 64: 678-691.

Wilkinson Richard and Marmot Michael (2003). Social Determinants of Health: The Solid Facts (2nd edition) Denmark: WHO Regional Office For Europe.

Wooden Mark and Watson Nicole (2007). The HILDA survey and its contribution to economic and social research (so far). Economic Record, 83: 208-231.

World Health Organization (WHO) (1946). Preamble to the Constitution of the World Health Organization as adopted by the International Health Conference, New York, 19-22 June, 1946. Official Records of the World Health Organization, No. 2: 100.

World Health Organization (WHO) (2014). Global Health Observatory Data Repository 2012 and 2013. www.who.int/gho/database/en/. 
This text is taken from Population Ageing and Australia's Future, edited by Hal Kendig, Peter McDonald and John Piggott, published 2016 by ANU Press, The Australian National University, Canberra, Australia. 